\title{
BISON FORAGING RESPONSE TO THE RISK OF WOLF Predation in a Spatially Heterogeneous Winter ENVIRONMENT:A PRELIMINARY ASSESSMENT
}

\author{
DANIEL MACNULTY $\uparrow$ UNIVERSITY OF MINNESOTA \\ ST. PAUL \\ DOUGLAS SMITH $\uparrow$ YELLOWSTONE NATIONAL PARK \\ YELLOWSTONE PARK $\uparrow \mathrm{WY}$
}

\begin{abstract}
$\downarrow$ INTRODUCTION
The impact of wolves on prey populations and plant communities in Yellowstone National Park (YNP) is a central question following wolf reintroduction. Plant responses due to wolf-caused changes in the number and behavior of prey may be one of the most controversial aspects of wolf reintroduction (Smith et al. 2002). Predators are known to benefit plants due to their direct and indirect effects on prey (Werner et al. 1983; Sih et al. 1985). Direct effects involve a reduction in the number of prey that feed on plants, while indirect effects involve changes in prey foraging behavior caused by the risk of predation, which is determined by predator presence and habitat characteristics (Lima and Dill 1990; Lima 1998a). Predators may have stronger effects on plants by scaring their prey than by consuming prey, because each predation event affects a single prey per unit time, while the risk of predation may cause many prey individuals to alter their foraging behavior in that same time period (Schmitz et al. 1997; Brown et al. 1999).
\end{abstract}

Predator-induced changes in prey foraging behavior involve tradeoffs whereby prey reduce predation risk at the expense of feeding time (Abrams 1984; Mangel and Clark 1986) and/or habitat use (Sih 1980; Werner 1991). Feeding tradeoffs occur when prey allocate more time to vigilance (Lima and Dill 1990), while habitat tradeoffs occur when prey spend more time in safer but food-poor areas (Lima 1998a, 1998b). Habitat tradeoffs reflect deviations from the Ideal Free Distribution (IFD) model of habitat choice (Fretwell and Lucas 1970), which predicts that the distribution of prey will match the distribution of resources among habitats (Milinski and Parker 1991). Predators disrupt the IFD; causing prey to undermatch resources when food-rich patches are also the riskier patches (Moody et al. 1996; Abrahams and Dill 1989).

Plants may benefit from both feeding time and habitat use trade-offs. A reduction in feeding time decreases time spent eating plants, while movement to different habitats alters the spatial distribution of plant impacts, even if overall feeding time remains unchanged (Turner and Mittelbach 1990; Schmitz and Booth 1997). Therefore, the first step in demonstrating a behaviorally-mediated trophic cascade is to show that prey modify foraging in response to predation risk (Miller and Kerfoot 1987; Turner 1997). Such behavioral evidence has been critical in supporting claims that predators indirectly benefit non-adjacent trophic levels in aquatic communities (Pettersson and Bronmark 1993). Equivalent evidence for terrestrial systems, particularly large mammals, has been lacking. 
Several recent studies propose that wolves in YNP benefit plants by changing prey behavior (Ripple and Larsen 2000; Laundre et al. 2001; Ripple et al. 2001; Ripple and Beschta 2003; Beschta 2003). Although these studies provide little, if any, behavioral information, they nonetheless argue that elk and bison decrease feeding time and avoid dangerous habitats in response to wolves. A number of earlier studies appear to support this assertion. For instance, lactating female moose and caribou switch to areas where diminished food quality and predation pressure exist (Edwards 1984; Bergerud et al. 1984; Ferguson et al. 1988; Heard et al. 1994). Most previous studies, however, fail to provide a clear demonstration that ungulates modify feeding and habitat use to reduce predation risk from wolves.

The purpose of this study was to determine how the risk of wolf predation affects the feeding behavior and habitat use of bison in Yellowstone National Park's Pelican Valley during late winter/early spring. This period was chosen because it is the best time to examine questions about the effects of predation risk on foraging in montane ungulates of temperate regions (Berger 1991). Bison, like other temperate ungulates, experience maximum energetic stress during this period (Meagher 1973), causing maximum vulnerability, and thus heighten behavioral sensitivity, to both predation and starvation. As a result, bison are most likely to balance safety against feeding in response to wolf predation risk at this time. In general, efforts to demonstrate food for safety tradeoffs are most likely to succeed during periods of food deprivation and energetic stress (Milinski 1993).

\section{$\uparrow \quad$ MeThODS \& STUDY AREA}

This study was conducted in YNP's Pelican Valley, which is located in the interior of YNP northeast of Yellowstone Lake. Behavioral observations were recorded from a centrally-located overlook. We collected bison time budget and activity data during individual focal watches. Each day was split into two 4-hour time zones (0800-1200, 1300-1700), within which focal individuals were selected randomly every hour and a variety of data were collected at 5-min intervals (Altmann 1974). Following focal selection, and prior to recording activity, observers noted information related to wolf presence as well as classified the focal's age and sex. Three to 5 members of the resident wolf pack (8-15 individuals) wore VHF radio-collars. Wolves were considered present in Pelican Valley if wolves were visually detected and/or audibly detected with radio- telemetry. Information on wolf presence included wolf location (UTM) and approximate date and time focal last encountered wolves. If wolves were present, their UTM location was recorded using a geographic information system (GIS) operated on a hand-held computer (Tripod Data Systems, Inc.). Bison age-sex class was determined as described by McHugh (1958) and Rutberg (1986). We identified calves ( $<1$ year), yearlings $(1<\&<2$ years), immature bulls ( $2-5$ years), and mature bulls $(>5$ years) and cows ( $>2$ years). The age-sex class and number of conspecifics that the subject was associated with during the focal period were also recorded. A subject was considered to be in a group if it was $<15 \mathrm{~m}$ from a conspecific.

Activity data was collected for each focal animal during each 1 -h period using a variable power (25-75x) spotting scope. Seven activity states (stand, walk, run, bed, scan, feed, and search) were recognized. An individual was considered feeding if its head was down and was biting forage. Searching was noted when an individual was either using its head and/or hooves to remove snow from a forage site, or when it was scanning the ground with its nose. Scanning was recorded when an individual looked from side to side after raising its head if foraging, or while standing. The age-sex class of conspecifics was recorded as described above. Habitat data include focal location (UTM), and snow depth (hoof, ankle, knee, belly, none). Activity data were directly entered into a hand-held computer.

For this report we analyzed observations of 61 focal bison ( 6 calves, 10 cows, 20 immature bulls, 19 mature bulls, 3 unknown bulls, and 3 unknown adults) recorded from 2002 to 2004 during a 2-3 week period in March of each year. Data on the size and distribution of bison grazing patches was derived from a single high-resolution $\left(2.5-\mathrm{m}^{2}\right)$ panchromatic satellite image taken by the Ikonos satellite (Space Imaging, Inc.) on March 14, 2003. Annual field visits to Pelican Valley in March since 1999 indicate that the size and distribution of grazing patches is consistent from year-to-year. As a result, we assumed for this analysis that the size and distribution of patches recorded by satellite in March 2003 was representative of patches in March 2002 and 2004.

\section{RESULTS}

Remote sensing imagery recorded by the IKONOS satellite on March 14, 2003 revealed that bison winter range in Pelican Valley is spatially heterogeneous due to a combination of geothermal 
and wind activity that produced a network of snowfree habitat patches (Fig. 1).

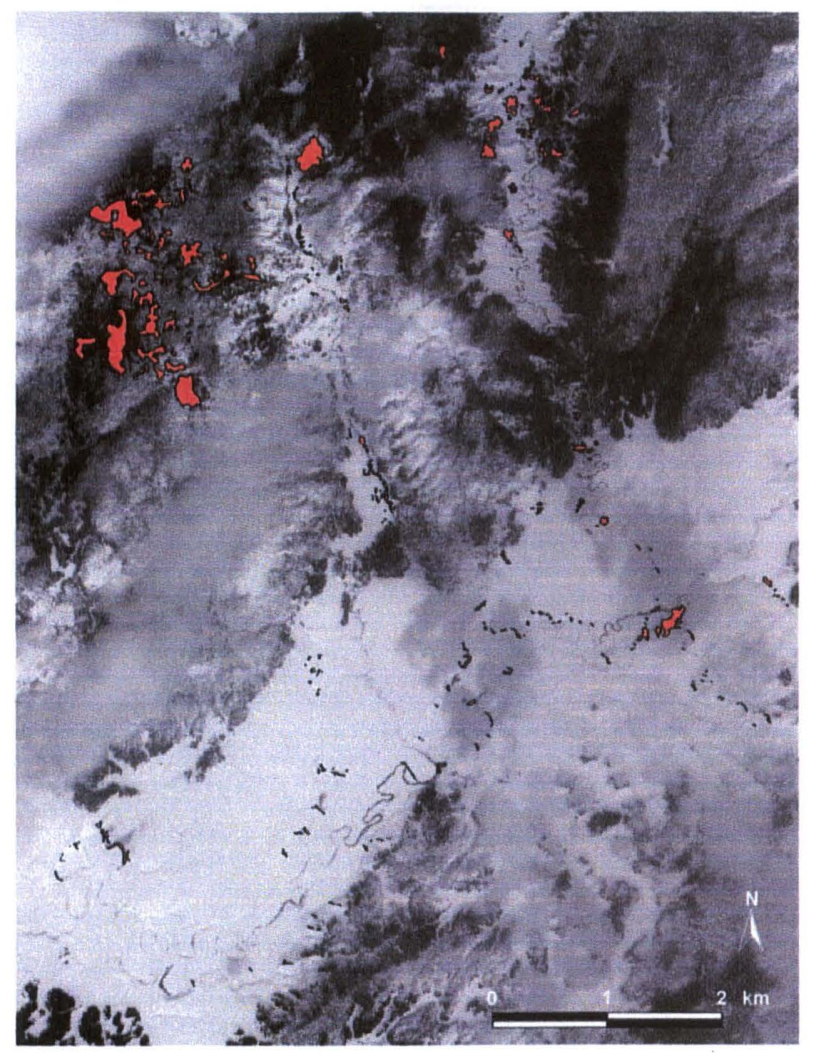

Fig. 1. IKONOS satellite image showing the entire network of grazing patches (red polygons) available to bison in Pelican Valley during late March.

We identified a total of 317 distinct habitat patches including 178 geothermal patches and 139 wind-swept patches. Most wind-swept patches were located in the main valley while the majority of geothermal patches were located in two drainages north of the main valley. Geothermal patches $\left(3508.54 \pm 690.96 \mathrm{~m}^{2}\right)$ were generally much larger than wind-swept patches $\left(270.19 \pm 52.17 \mathrm{~m}^{2} ; t=\right.$ 8.12 , d.f. $=315, P<0.001$ ).

Small patches $\left(\leq 200 \mathrm{~m}^{2}\right)$ were more dangerous than large patches $\left(>200 \mathrm{~m}^{2}\right)$. This is because wolves tended to attack bison on small patches more often than bison on large patches $\left(\chi^{2}=\right.$ 2.31, d.f. $=1, P=0.13$; Fig. 2). Small patches hindered the ability of bison to maneuver against wolves, thus making them more vulnerable to wolf predation. Bison appeared to respond to this spatial variation in predation risk by feeding in small patches when wolves were absent from Pelican Valley, and then shifting to large patches when wolves were present. Thus, there was a significant interactive effect of spatial and temporal predation risk on bison feeding behavior $\left(F_{1,41}=4.45, P=0.04\right.$; Fig. 3$)$. Future analyses will examine if this pattern differs with respect to bison age and sex.

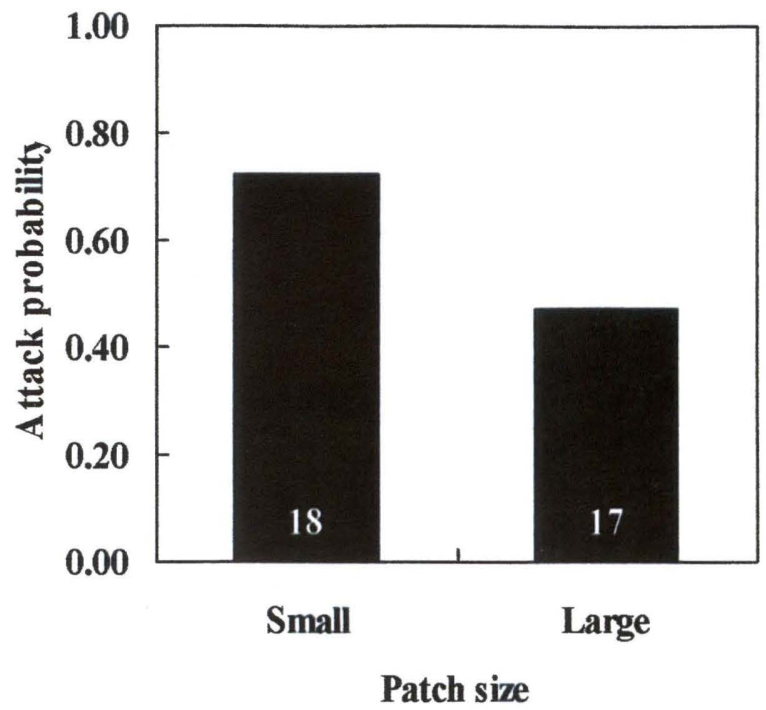

Fig. 2. Probability that wolves attacked bison occupying small $(\leq$ $200 \mathrm{~m}^{2}$ ) and large $\left(>200 \mathrm{~m}^{2}\right)$ patches. Sample sizes (no. of observed wolf-bison encounters) given at the base of each bar.

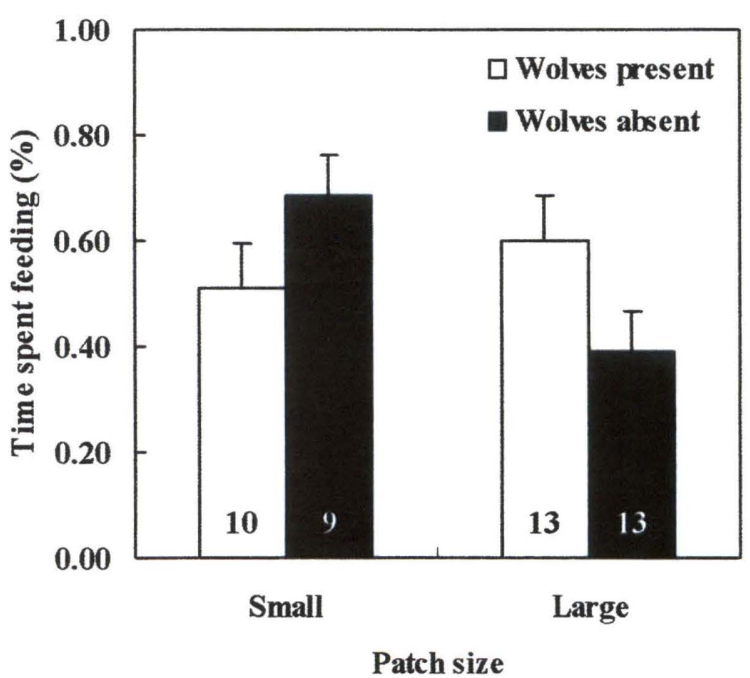

Fig. 3. Proportion of time bison spent feeding in small $\left(\leq 200 \mathrm{~m}^{2}\right)$ and large $\left(>200 \mathrm{~m}^{2}\right)$ patches in the presence and absence of wolves. Sample sizes (no. of focal individuals) given at the base of each bar. 
We hypothesized that bison spent more time feeding in small patches than large patches in the absence of wolves because intraspecific feeding competition was less on small patches. The size of the herd associated with each focal bison tended to be related to the size of the patch the herd occupied. That is, large herds occupied large patches and small herds occupied small patches (Mann-Whitney $U=$ $316, P=0.11$; Fig. 4). Although competition in small patches with small herds may be proportionate to competition in large patches with large herds, field observations suggest that herd size increases nonlinearly with patch size. Thus, feeding competition in small patches is probably less than in large patches where bison are more abundant.

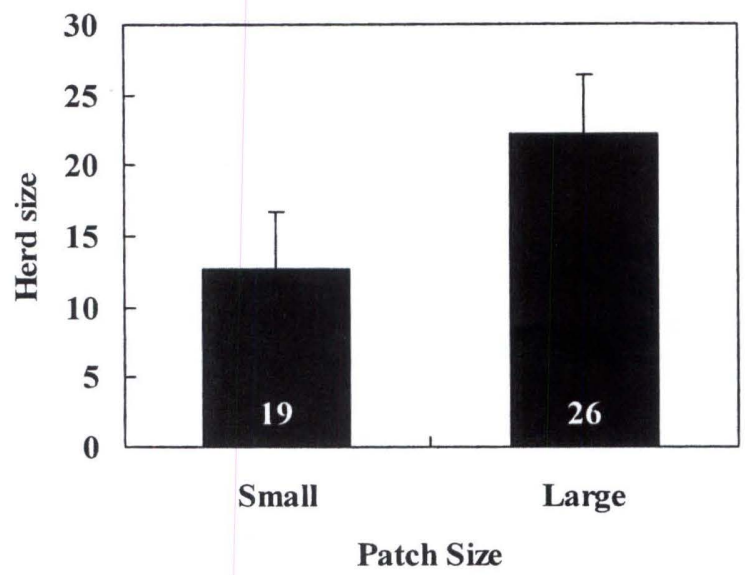

Fig. 4. Relation between a focal individual's herd size and the size of the grazing patch occupied by the focal. Sample sizes (no. of focal individuals) given at the base of each har).

However, bison feeding time did not decrease linearly with increasing herd size. Rather, an individual's feeding time initially increased with herd size until reaching a plateau of about 30 individuals and then decreased as herd size exceeded $30(b=-0.0003 \pm 0.0001, t=-1.85, P=0.07$; Fig. 5$)$. As a result, bison appeared to maximize feeding time by associating with herds that contained around 30 individuals. Nevertheless, decreasing feeding time in herds larger than 30 was consistent with our hypothesis that bison fed in small patches to reduce competition and enhance per capita forage intake.

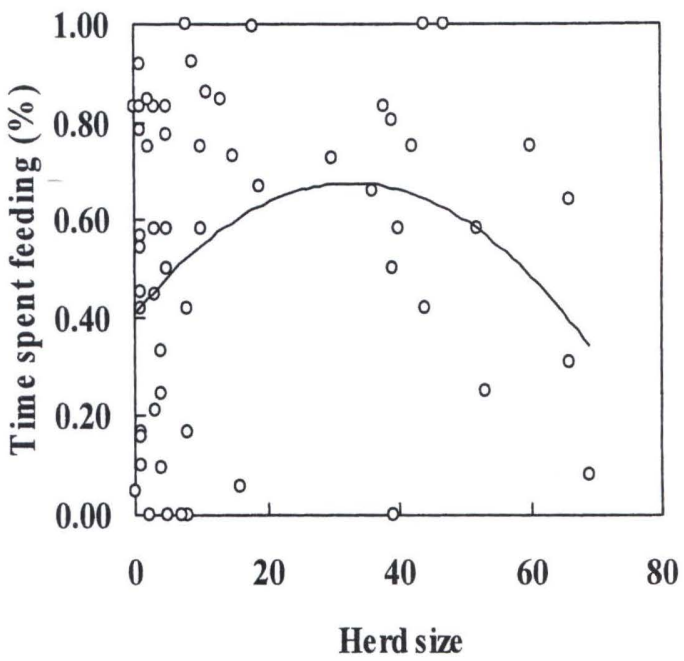

Fig. 5. Effect of bison herd size on individual feeding time.

The initial increase in bison feeding time with herd size appeared to stem from the heightened risk of predation experienced by small herds. Wolves were more likely to attack small herds than large herds $(b=-0.021 \pm 0.007, t=-3.11, P=0.002$; Fig. 6 ), and individuals within these herds responded to this greater risk by spending more time scanning $(b=$ $0.0001 \pm 0.0001, t=2.21, P=0.03$; Fig. 7). Bison feeding in small herds therefore sacrificed food intake for safety by feeding less and scanning more. Nevertheless, for individuals within herds containing fewer than 30 members, herd size had a positive effect on feeding time most likely because it allowed individuals to allocate less time to scanning for wolves and more time to feeding. Decreased feeding and increased scanning among individuals in herds with more than 30 members was likely due to feeding competition since wolf attack probability decreased with increasing herd size.

\section{DISCUSSION}

Winter range for bison in YNP's Pelican Valley was spatially heterogeneous with respect to wolf predation risk. In particular, small $\left(\leq 200 \mathrm{~m}^{2}\right)$ geothermal sites and wind-swept slopes were more dangerous than larger ones $\left(>200 \mathrm{~m}^{2}\right)$ because wolves were more likely to attack bison on small patches. 
Bison were probably more vulnerable on small patches because they had less defensible space available to effectively maneuver against wolves. Bison appeared to alter habitat use in response to this spatial variation in wolf predation risk. In the absence of wolves, bison spent more time feeding in small patches than large patches. When wolves were present, however, bison spent more time feeding in large patches.

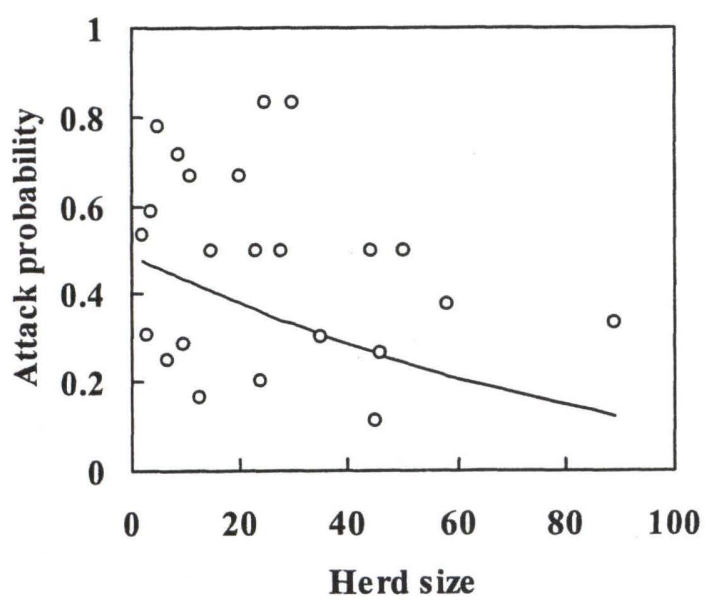

Fig. 6. Effect of bison herd size on the risk of wolf attack.

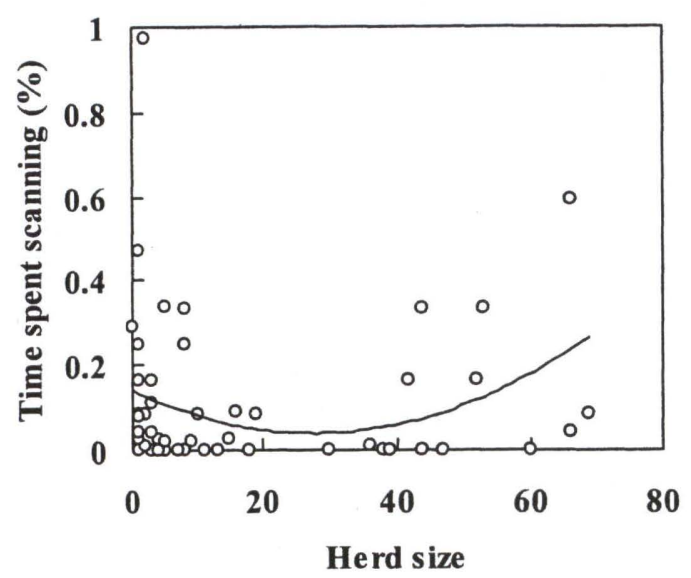

Fig. 7. Effect of bison herd size on individual scanning time.
Small patches generally contained fewer bison than large patches. As a result, small patches were probably more profitable than large patches because of reduced feeding competition. Feeding competition among bison is known to be highest when forage is sparse and when there is significant travel time between suitable grazing patches (Rutberg 1986). Bison therefore probably used small patches when wolves were absent to increase food-intake but returned to large patches when wolves were present to reduce predation risk at the expense of feeding. This appears to represent a classic food-for-safety trade-off in which prey sacrifice food intake to reduce predation risk (Lima 1998a). This preliminary finding is particularly interesting because it is consistent with recent studies elsewhere in the Greater Yellowstone Ecosystem that show how changes in prey behavior in response to wolf predation risk is determined by the interaction between spatial (e.g. small versus large patch) and temporal (wolves present versus absent) risk (Creel \& Winnie 2005). Had we only examined the effects of spatial or temporal risk we would have arrived at a false conclusion that bison feeding behavior was unaffected by wolf predation risk. Clearly, both types of risk need to be considered when assessing the influence of wolf predation risk on ungulates.

Although bison probably spent more time feeding in small patches when wolves were absent because herds on these patches were also small, thus reducing feeding competition, we did not find a linear relationship between individual feeding time and herd size. That is, feeding time did not decrease linearly with herd size. Rather, as herd size increased, individual feeding time initially increased until reaching a plateau at about 30 individuals and then decreased. The initially positive effect of herd size on feeding time may stem from the benefit of collective predator detection (e.g. the 'many-eyes' response). Specifically, individuals allocated more time to feeding and less time to scanning as the number of conspecifics increased. Individuals in small herds were probably more vigilant because wolves were more likely to attack small herds than large herds. As feeding time began to decline once herd size exceeded about 30 individuals, the competitive costs of group feeding appeared to outweigh the antipredator benefits of grouping. Decreased feeding and increased scanning among individuals in herds with more than 30 members was most likely the result of increased feeding competition since the risk of wolf attack decreased with increasing herd size. Increased scanning among individuals in large herds probably reflected more feeding interruptions due to competition for scarce forage. 
The effects of herd size on individual feeding time suggest that bison use of small patches in the absence of wolves also reflects the conflicting demands of feeding and predator-avoidance. In this case, bison must balance the gains of foraging in a small patch that contains few competitors with the costs of spending more time scanning than feeding if the number of conspecifics is too small to confer a 'many-eyes' benefit. Consequently, in order to maximize feeding time in small patches, a bison must choose to forage in a herd that is not too big as to decrease feeding time, but not so small as to require increased scanning to avoid predation. However, such decision-making is undoubtedly influenced by a bison's relative vulnerability to wolf predation with respect to it age and sex. For instance, mature bulls probably can afford to forage in small patches without regard to group size and its 'many-eyes' benefit because bulls are nearly invulnerable to wolf predation (MacNulty, unpublished) and do not rely on vigilance to avoid predation. On the other hand, group size considerations may be paramount for a yearling bull to forage in a small patch since they are highly vulnerable to predation (MacNulty, unpublished). Future analyses will examine the effects of bison age and sex on foraging responses to wolf predation risk in greater detail.

\section{FUTURE DIRECTIONS}

Results described in this report are preliminary pending additional sampling and analysis. We aim to increase our sample size by conducting additional focal-animal sampling in March 2006. We are also developing a spectral model that relates high-resolution $\left(2-\mathrm{m}^{2}\right)$ multi-spectral satellite data (Quickbird, DigitalGlobe, Inc.) to ground-based measurements of patch biomass and total nitrogen to quantitatively describe spatial variation in bison forage availability. We intend to use this information to more closely examine how bison make trade-offs between foraging and predation risk. In March 2006 we will also be measuring the temporal risk of wolf predation (presence versus absence) at a much finer-scale using data from a recently deployed GPS radio-collar that records the position of the instrumented wolf every other hour.

\section{$\uparrow \quad$ LiteratURE CITED}

Abrams, P.A. 1984. Foraging time optimization and interactions in food webs. Am. Nat. 124:8096.

Abrahams, M.V. and L.M. Dill. 1989. A determination of the energetic equivalence of the risk of predation. Ecology 70:9991007.

Altmann, J. 1974. Observational study of behaviour: sampling methods. Behaviour 49:227-265.

Berger, J. 1991. Pregnancy incentives, predation constraints and habitat shifts: experimental and field evidence for wild bighorn sheep. Animal Behavior 41:61-77.

Bergerud, A.T., Butler, H.E. and Miller, D.R. 1984. Antipredator tactics of calving caribou: dispersion in mountains. Canadian Journal of Zoology 62:1566-1575.

Beschta, R.L. Cottonwoods, elk, and wolves in the Lamar Valley of Yellowstone National Park. Ecological Applications 13:1295-1309.

Brown, J.S., J.W. Laundre, and M. Gurung. 1999. The ecology of fear: optimal foraging, game theory, and trophic interactions. Journal of Mammalogy 80:385-399.

Creel, S. and J.A. Winnie 2005. Responses of elk herd size to fine-scale spatial and temporal variation in the risk of predation by wolves. Animal Behaviour 69:1181-1189.

Edwards J. 1983. Diet shifts in moose due to predator avoidance. Oecologia 60:185-189.

Ferguson et al. 1988. Predation risk and habitat selection in the persistence of a remnant caribou population. Oecologia 76:236-245.

Fretwell, S.D. and H.J. Lucas. 1970. On territorial behaviour and other factors influencing habitat distribution in birds. Acta Biotheoretica 19:16-36. 
Heard D.C., T.M. Williams, and D.A. Melton.1996. The relationship between food intake and predation risk in migratory caribou and implications to caribou and wolf population dynamics. Rangifer. Special Issue, No. 9:3744.

Laundre, J.W., L. Hernandez, and K.B. Altendorf. 2001. Wolves, elk, and bison: reestablishing the "landscape of fear" in Yellowstone National Park, U.S.A. Can. J. of Zool. 79:1401-1409.

Lima, S.L. 1998a. Stress and decision-making under the risk of predation: recent developments from behavioral, reproductive, and ecological perspectives. Advances in the Study of Behav. 28: 215-290.

Lima, S.L. 1998b. Nonlethal effects in the ecology of predator-prey interactions. Bioscience 48:25-34.

Lima, S.L. and L.M. Dill. 1990. Behavioral decisions made under the risk predation: a review and prospectus. Canadian Journal of Zoology 68:105-112.

Mangel, M., and C.W. Clark. 1986. Toward a unified foraging theory. Ecology 67:1127-1138.

McHugh, T. 1958. Social behavior of the American buffalo (Bison bison bison). Zoologica 43:140.

Meagher, M. 1973. The bison of Yellowstone National Park. Scientific Monograph No. 1 Department of the Interior, National Park Service.

Milinski, M. 1993. Predation risk and feeding behavioir. In Behaviour of Teleost Fishes (T. Pitcher, editor), pp. 236-252. Croom Helm, London.

Milinski, M. and G.A. Parker. 1991. Competition for resources, in Behavioral Ecology: An Evolutionary Approach, $3^{\text {rd }}$ ed. (J.R. Krebs and N.B. Davies, editors), pp. 137-168. Blackwell, Oxford.
Miller, T.E., and W.C. Kerfoot. 1987. Redefining indirect effects, in Predation: direct and indirect impacts on aquatic communities (W.C. Kerfoot and A. Sih, editors), pp. 3337. University Press of New England, Hanover, New Hampshire, USA.

Moody, A.L., A.I. Houston, and J.M. McNamara. 1996. Ideal free distributions under predation risk. Behavioral Ecology and Sociobiology 27:17-21

Pettersson, L.B., and C. Bronmark. 1993. Trading off safety against food: state dependent habitat choice and foraging in crucian carp. Oecologia 95:353-357.

Ripple, W.J., and E.J. Larsen. 2000. Historic aspen recruitment, elk, and wolves in Northern Yellowstone National Park, USA. Biological Conservation 95:361-370.

Ripple, W.J., E.J. Larsen, R.A. Renkin, and D.W. Smith. 2001. Trophic cascades among wolves, elk and aspen on Yellowstone National Park's northern range. Biological Conservation 102:227-234.

Ripple, W.J. and R.L. Beschta. 2003. Wolf reintroduction, predation risk, and cottonwood recovery in Yellowstone National Park. Forest Ecology \& Management 184:299-313.

Rutberg, A.T. 1986. Dominance and its fitness consequences in American bison cows. Behav. 96:62-91.

Schmitz, O.J., and G. Booth. 1997. Modeling food web complexity: the consequences of individual-based, spatially explicit behavioral ecology on trophic interactions. Evol. Ecology 11:379-398.

Schmitz, O.J., A.P. Beckerman, K.M. O'Brien. 1997. Behaviorally mediated trophic cascades: effects of predation risk on food web interactions. Ecology 78:1388-1399.

Sih, A. 1980. Optimal behavior: can foragers balance two conflicting demands? Science 210:1041-1043. 
Sih, A., P. Crowley, M. McPeek, J. Petranka, and K. Strohmeier. 1985. Predation, competition, and prey communities: a review of field experiments. Annual Review of Ecology and Systematics 16:269-311.

Smith, D.W., R.O. Peterson, and D.B. Houston. 2003. Yellowstone after wolves. Bioscience 53:330-340.

Turner, A.M. 1997. Contrasting short-term and longterm effects of predation risk on consumer habitat use and resource dynamics. Behavioral Ecology 8:120-125.

Turner, A.M., and G.G. Mittelbach. 1990. Predator avoidance and community structure: interactions among piscivores, planktivores, and plankton. Ecology 71:2241-2254.
Werner, E.E., J.F. Gilliam, D.J. Hall, and G.G. Mittelbach 1983. Experimental tests of optimal habitat use in fish: the role of relative habitat profitability. Ecology 64:1525-1539.

Werner, E.E. 1991. Nonlethal effects of a predator on competitive interactions between two anuran larvae. Ecology 72:1709-1720 